\title{
AN APPROACH TO THE DETERMINATION OF REACTIONS IN STATICALLY DETERMINATE BEAMS
}

\author{
A. Mohammed ${ }^{1}$ \\ ${ }^{I}$ Reader, Department of Civil Engineering, Abubakar Tafawa Balewa University, Bauchi, Nigeria
}

\begin{abstract}
The challenge in the teaching of basic engineering fundamentals to students of engineering has become a topical issue and main issue to engineering institutions and the civil engineering industry at large. To this end, three rules are proposed to aid in the determination of reactions for simply supported beams of varying configurations; namely a simple beam carrying a point load, uniformly distributed load and couple and a simple beam with an overhang. The rules derive from the physical geometry of the beam and are therefore quasi-qualitative in nature. Three worked examples are given to illustrate how the rules will be used. It is seen that the rules will greatly aid understanding of structural behaviour by making students and young engineers develop a better appreciation of structural analysis.
\end{abstract}

Keywords: Structural, beams, analysis, and reactions.

\section{INTRODUCTION}

The problem of a gap in the understanding the structural behaviour by graduate engineers has been reported by many authors[1-4], who have advocated a more qualitative style teaching for the understanding of structural analysis by students. This paper presents principles of qualitative/quasiqualitative analysis as basis for describing the principles of an alternative approach to the determination of the reactions in simple beams. Four case studies are considered which cover the various types of loads and boundary conditions applicable to simple beams namely; a simple beam with point load, another with a UDL, a beam with an overhang and lastly a beam carrying a couple

\section{CASE 1- POINT LOAD}

The simplest case of a simple beam loaded with single point load is shown in Figure 1. It is known from Newton's third law of motion, that in order to maintain equilibrium of the beam there must be reactions at $\mathrm{A}$ and $\mathrm{B}$. It is seen from the figure that the load $\mathrm{P}$ is closer to $\mathrm{A}$ than $\mathrm{B}$, which suggests that the reaction at $\mathrm{A}$ must be greater than that at $\mathrm{B}$ to maintain equilibrium. Thus it implies that reactions must be a function of these distances or in other terms the reactions must be in proportion to their distances from the load point. Since the Newton's third law states that action and reaction are them same and opposite, it suggest that for the determination of the reaction at $\mathrm{A}$, the load $\mathrm{P}$ must be multiplied by the ratio $\frac{\mathrm{b}}{\mathrm{L}}$ and similarly for the determination of the reaction at $\mathrm{B}$, the load $\mathrm{P}$ must be multiplied by the ratio $\frac{\mathrm{a}}{\mathrm{L}}$. Hence it is seen that the value of a reaction is simply a function of how far the load is from the other reaction.
Also using statics, it can be shown that the value of the reaction at $\mathrm{B}, \mathrm{R}_{\mathrm{B}}$ is $\frac{\mathrm{P} . \mathrm{a}}{\mathrm{L}}$ as shown in Equation 1. It is evident from Equation 1 that the value of the reaction is the

product of the point load multiplied by the ratio $\frac{\mathrm{a}}{\mathrm{L}}$, which is simply the distance in between the point load and the other

reaction at A. Similarly the reaction at $A, R_{A}$ is $\frac{P . b}{L}$ as shown in Equation 2.

Thus it can be said that, If a simple beam is loaded by a system of loads, the value of a reaction is the summations of the product of each of the loads or their resultant (in the case of distributed loads) and their distance apart from the other reaction divided by the span.

\section{Rule 1}

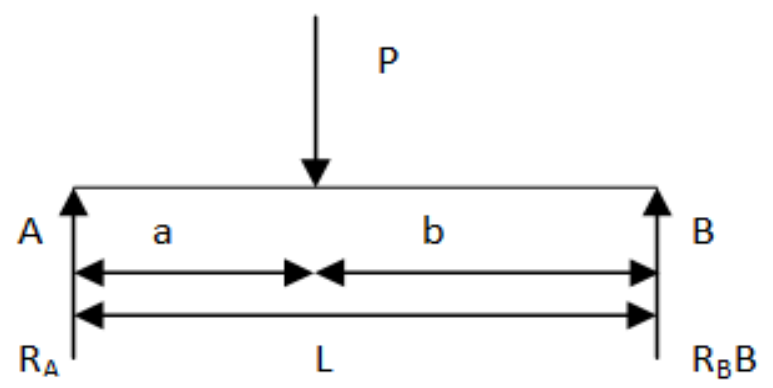

Fig -1: A simple beam loaded with a point load.

$$
\begin{gathered}
\Sigma \mathrm{M}_{\mathrm{A}}=0, \\
P \times a-R_{B} . L=0
\end{gathered}
$$




$$
\mathrm{R}_{\mathrm{B}}=\frac{\mathrm{Pa}}{\mathrm{L}}
$$

Similarly $\mathrm{R}_{\mathrm{A}}=\frac{\mathrm{Pb}}{\mathrm{L}}$

\section{CASE 2- UDL}

Figure 2 shows a simple beam carrying a UDL at distance a from the left hand support. As discussed in the last section, it can be shown using statics that the reaction at $B, R_{B}$ is given by wa. $\frac{(\mathrm{a} / \mathrm{2})}{\mathrm{L}}$ as shown in Equation 3. The term wa is the equivalent point load due to UDL acting at $\mathrm{a} / 2$ from A, which is equal to the term in brackets from Equation 3 . Thus it seen again that the value of the reaction at B is the equivalent point load multiplied by the distance apart from the other reaction divided by the span of the beam. In the same way, the reaction at $A, R_{A}$ is wa. $\frac{(a / 2+b)}{L}$ as shown in Equation 4. Where wa is as defined earlier, and $(a / 2+b)$ is the distance apart between the two supports.

Thus it is seen that both the reactions at $\mathrm{A}$ and $\mathrm{B}$ respectively agree with our preposition that the value of a reaction is simply the product of the load(s) multiplied by the distance in between the reactions divided by the span of the beam.

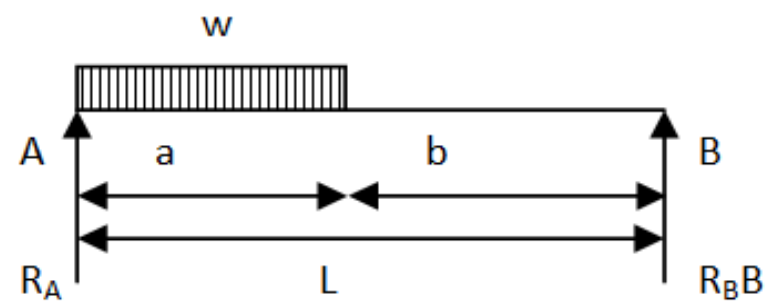

Fig -2: A simple beam loaded with a UDL.

$\Sigma \mathrm{M}_{\mathrm{A}}=0$

$\mathrm{W} \frac{\mathrm{a}^{2}}{2}-\mathrm{R}_{\mathrm{B}} \cdot \mathrm{L}=0$

$\mathrm{R}_{\mathrm{B}}=\frac{\mathrm{w} \frac{\mathrm{a}^{2}}{2}}{\mathrm{~L}}=\mathrm{wa} \cdot \frac{\left(\mathrm{a} / \mathrm{C}^{2}\right)}{\mathrm{L}}$

Similarly $\mathrm{R}_{\mathrm{A}}=\mathrm{wa} \cdot \frac{(\mathrm{a} / 2+\mathrm{b})}{\mathrm{L}}$

\section{CASE 3- SIMPLE BEAM WITH AN OVERHANG}

Figure 3 shows a simple beam carrying a UDL on its overhang. Using statics it can be shown that the Reaction at

$\mathrm{B}$ is $-\frac{\mathrm{wa}(\mathrm{a} / \mathrm{2})}{\mathrm{L}}$ as expressed in Equation 5. Where the term wa is simply the equivalent point load due to the UDL

acting at $\mathrm{a} / 2$ from $\mathrm{A}$. Thus the value of the reaction at $\mathrm{B}$ again corresponds to the equivalent point load multiplied by the distance apart from the other reaction divided by the span of the beam, but this time the value is negative because the load is wholly carried on the overhang that is adjacent to the other support at A.

Similarly the reaction at $A$, can be shown to be $\frac{\mathrm{wa}(\mathrm{a} / 2+\mathrm{L})}{\mathrm{L}}$

as shown in Equation 6, where wa is equivalent point load due to the UDL acting at $a / 2$ from $A$, and $\mathrm{L}$ is the distance apart between the two supports.

Again it is seen that the value of both the reactions at A and B concur with our preposition, but because the it could either be positive or negative it could be said that

For a simple beam carrying a load on its overhang, the value of the reaction adjacent to the overhang is simply the positive product of the load and the distance apart from the other reaction divided by the span of the beam, while the other reaction is simply the negative product of the load and the distance apart from the other reaction divided by the span of the beam.

Rule 2

w

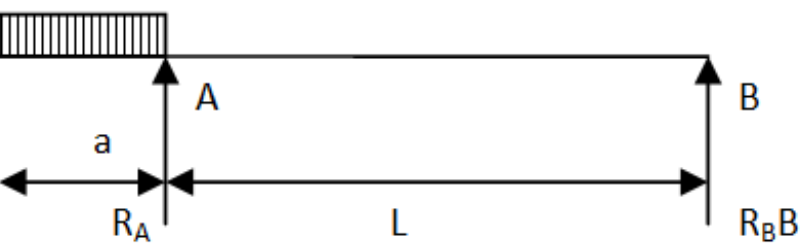

Fig 3 - A simple beam carrying a UDL on its overhang.

$$
\Sigma \mathrm{M}_{\mathrm{A}}=0 \text {, }
$$

$-\mathrm{wa} \cdot \frac{\mathrm{a}}{2}-\mathrm{R}_{\mathrm{B}} \cdot \mathrm{L}=0$

$\mathrm{R}_{\mathrm{B}}=-\frac{\mathrm{wa}(\mathrm{a} / 2)}{\mathrm{L}}$ 
Similarly $\mathrm{R}_{\mathrm{A}}=\frac{\mathrm{wa}(\mathrm{a} / 2+\mathrm{L})}{\mathrm{L}}$

\section{CASE 4 - SIMPLE BEAM WITH A COUPLE}

Lastly Figure 4 shows a simple beam carrying a couple of magnitude $\mathrm{M}$ in an anticlockwise orientation. Using statics it can be shown that the value of the reaction at $\mathrm{B}$ is simply $-\frac{\mathrm{M}}{\mathrm{L}}$

$\mathrm{L}$ as expressed in Equation 7. Similarly the reaction at A $=\frac{\mathrm{M}}{\mathrm{L}}$ value of a reaction is simply the magnitude of the couple divided by the span. However depending on the orientation (direction) of the couple it could have either a positive or negative contribution to the reaction. If the couple is in the anticlockwise sense as it is the case here (that is in the direction of the left hand support) then the it will have a positive contribution to the left hand reaction. The reverse will hold if the couple is in the opposite sense.

Thus in the case of a simple beam carrying a couple in the anticlockwise sense, it can be said that the value of the reaction at the left hand support is simply the couple divided by the span of the beam, while the other reaction is the negative value of the couple divided by the span of the beam, the reverse holds if the couple is in the opposite sense.

\section{Rule 3}

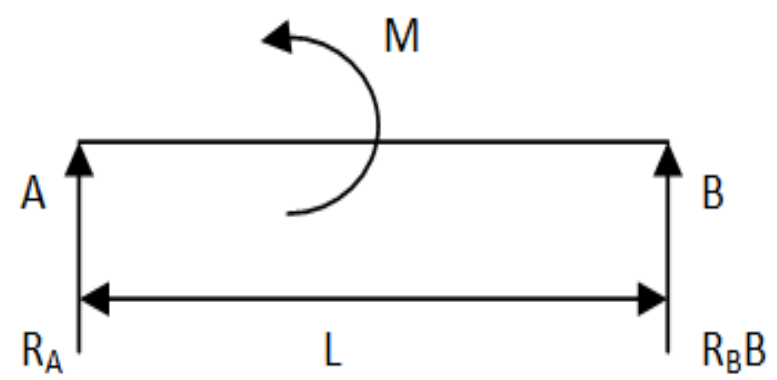

Fig 4 - A simple beam carrying a couple of magnitude M.

$$
\begin{gathered}
\Sigma \mathrm{M}_{\mathrm{A}}=0, \\
-\mathrm{R}_{\mathrm{B}} \cdot \mathrm{L}-\mathrm{M}=0 \\
\mathrm{R}_{\mathrm{B}}=-\frac{\mathrm{M}}{\mathrm{L}} \\
\text { Similarly } \mathrm{R}_{\mathrm{A}}=\frac{\mathrm{M}}{\mathrm{L}}
\end{gathered}
$$

\section{EXAMPLES}

Example1

Using Rule 1

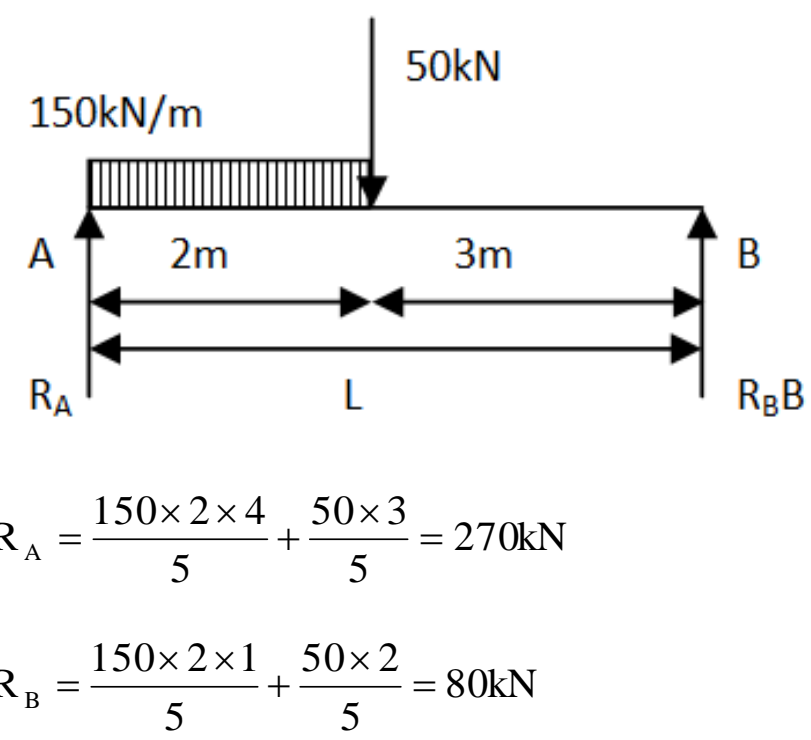

Example 2

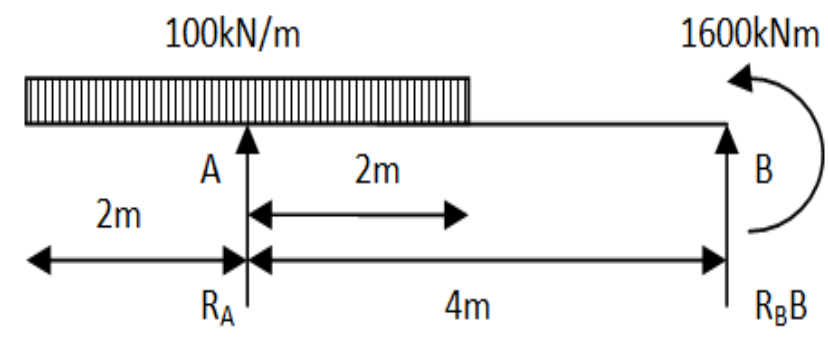

Using Rules 2 \& 3

$$
\begin{aligned}
& \mathrm{R}_{\mathrm{A}}=\frac{100 \times 4 \times 4}{4}+\frac{1600}{4}=800 \mathrm{kN} \\
& \mathrm{R}_{\mathrm{B}}=-\frac{100 \times 4 \times 0}{4}-\frac{1600}{4}=-400 \mathrm{kN}
\end{aligned}
$$

\section{Example 3}

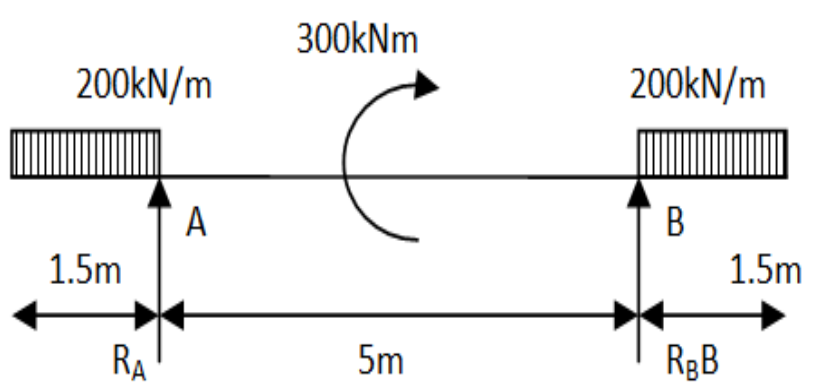


Using Rules $2 \& 3$

$\mathrm{R}_{\mathrm{A}}=\frac{200 \times 1.5 \times 5.75}{5}-\frac{300}{5}-\frac{200 \times 1.5 \times 0.75}{5}=240 \mathrm{kN}$
$\mathrm{R}_{\mathrm{B}}=-\frac{200 \times 1.5 \times 0.75}{5}+\frac{300}{5}+\frac{200 \times 1.5 \times 5.75}{5}=360 \mathrm{kN}$

\section{CONCLUSION}

These rules derive from the physical descriptions of the beams and loads in question, thus it is expected that they will aid in better understanding of the behaviour of the beam before even the reactions are calculated. Because at a glance one will be able to appreciate the contributions of each load to reactions in a simple beam, a beam with a couple or overhang. These rules are not expected to replace the use of statics but to serve as an aid to the understanding of structural analysis. It will further aid in laying emphasis on understanding structural behaviour rather than just calculations.

A further benefit of this approach is that it also aids in the appreciation of the contribution of each load to either reaction as shown in the examples. This is necessary because in the final analysis, what matters is for engineers to understand structural behaviour so that they will be able to know instinctively what could go wrong with our calculations. This is more so very important these days where structural analyses are performed by the use of computers.

\section{REFERENCES}

[1] Brohn DM, Cowan J.: 'Teaching towards an improved understanding of structural behaviour', The Structural Engineer, 55/1, 1977, p 9-17

[2] Jennings A, Gilbert S.: 'Where now with the teaching of structures', The Structural Engineer, 66/1, 1988, p 3-7

[3] Morreau PM.: 'Understanding structural behaviour', The Structural Engineer, 68/15, 1990, p 299-300

[4] Ji T, Bell A.: "Seeing and touching structural concepts", Taylor and Francis, Oxon, 2008.

\section{BIOGRAPHY}

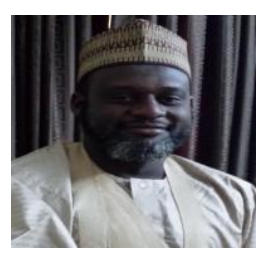

Dr. Abbagana Mohammed is a Reader in Structural Engineering and is currently with the Department of Civil Engineering, Abubakar Tafawa Balewa University, Bauchi in Nigeria. 